\title{
Association between Insulin Resistance and Cardiovascular Risk Factors in Polycystic Ovary Syndrome Patients
}

\section{Associação entre resistência à insulina e fatores de risco cardiovascular em pacientes com síndrome dos ovários policísticos}

\author{
Miriam da Silva Wanderley ${ }^{1}$ Lara Cristina Ribeiro Pereira ${ }^{1}$ Carla Borges Santos ${ }^{1}$ \\ Vinícius Santos da Cunha ${ }^{1}$ Mariam Viviane Jovino Neves ${ }^{1}$
}

${ }^{1}$ Gynecology and Obstetrics, Faculty of Medicine, Hospital

Universitário de Brasília, Universidade de Brasília, Brasília, DF, Brazil

Address for correspondence Miriam da Silva Wanderley, Universidade de Brasília, Campus Universitário Darcy Ribeiro, Asa Norte, Brasília, DF, 70210-900, Brazil (e-mail: miriamsw@unb.br).

Rev Bras Ginecol Obstet 2018;40:188-195.

\begin{abstract}
Objective To analyze the association between the indirect methods of evaluating insulin resistance (IR) and blood pressure, anthropometric and biochemical parameters in a population of polycystic ovary syndrome (PCOS) patients.

Methods Cross-sectional study performed at the Hospital Universitário de Brasília (HUB, in the Portuguese acronym) involving PCOS patients diagnosed from January 2011 to January 2013. Four indirect methods, namely, fasting blood insulin level, fasting glucose/insulin ratio $(G / I)$, homeostatic model-assessment-insulin resistance (HOMA-IR), and the quantitative insulin sensitivity check index (QUICKI), were used to obtain the IR diagnosis. The data were analyzed using the test of proportions, the Chisquare test, and Fisher exact test, when indicated.

Results Out of the 83 patients assessed, aged $28.79 \pm 5.85$, IR was found in 51.81 $66.2 \%$ of them using the G/I ratio and the QUICKI, respectively. The test of proportions did not show a significant difference between the methods analyzed. The proportion of IR diagnoses was statistically higher in obese women than in women with normal body mass index (BMI). We observed a statistically significant association between all the methods for diagnosing IR and BMI, waist circumference (WC) and lipid

\section{Keywords}

- polycystic ovary syndrome

- insulin resistance

- body mass index

- waist circumference

- lipid accumulation product accumulation product (LAP). With regards to arterial hypertension (AH), we observed a significant association according to three methods, with the exception of the ratio $\mathrm{G} / \mathrm{I}$.

Conclusion Insulin resistance prevalence varied according to the diagnostic method employed, with no statistical difference between them. The proportion of IR diagnoses was statistically higher in obese women than in women with normal BMI. We observed a significant association between IR and WC, BMI, LAP, as well as dyslipidemia and AH in a high proportion of patients.
\end{abstract}

received

July 25,2017

accepted

March 6, 2018
DOI https://doi.org/

10.1055/s-0038-1642634. ISSN 0100-7203.
Copyright ( $\odot 2018$ by Thieme Revinter Publicações Ltda, Rio de Janeiro, Brazil
License terms

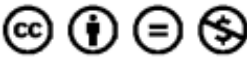




\section{Resumo}

\section{Palavras-Chave}

- síndrome de ovários policísticos

- resistência à insulina

- índice de massa corporal

- circunferência da cintura

- produto de acumulação lipídica
Objetivo Analisar a associação entre os métodos indiretos de avaliação de resistência à insulina (RI) e parâmetros pressóricos, antropométricos e bioquímicos em uma população de pacientes com síndrome dos ovários policísticos (SOP).

Métodos Estudo transversal realizado no Hospital Universitário de Brasília (HUB), envolvendo pacientes que apresentaram o diagnóstico de SOP no período de janeiro de 2011 a janeiro de 2013. O diagnóstico de RI foi obtido por meio de quatro métodos indiretos: insulinemia de jejum, relação glicemia de jejum/insulinemia de jejum (G/I), avaliação da resistência à insulina através do modelo homeostático (HOMA-IR) e índice quantitativo de sensibilidade à insulina (QUICKI). Os dados foram analisados utilizando o teste de proporções, o teste do Qui-quadrado e o teste exato de Fisher, quando indicado.

Resultados Foram avaliadas 83 pacientes com idade média de $28,79 \pm 5,85$ anos. A RI foi diagnosticada em 51,81-66,27\% dos casos pela relação G/I e QUICKI, respectivamente, e o teste de proporções não evidenciou diferença significativa entre os métodos analisados. A proporção de diagnósticos de RI foi estatisticamente maior em mulheres obesas em comparação à proporção de mulheres com índice de massa corporal (IMC) normal. Foi observada uma associação estatisticamente significativa entre todos os métodos diagnósticos de RI e IMC, circunferência da cintura (CC) e produto de acumulação lipídica (LAP). Quanto à hipertensão arterial (HA), foi observada associação significativa de acordo com três métodos, com exceção da relação G/I.

Conclusão A prevalência de RI variou conforme o método diagnóstico utilizado, mas não houve diferença estatística entre eles. A proporção de diagnósticos de IR foi maior nas mulheres obesas do que naquelas com peso normal. Foi observada associação significativa entre RI e CC, IMC e LAP, assim como com dislipidemia e HA em uma proporção elevada de pacientes.

\section{Introduction}

Polycystic ovary syndrome (PCOS) is the most common endocrine disorder affecting women in childbearing age. It is a heterogeneous disorder whose pathogenesis is not well understood despite evidence of complex interaction with genetic, behavioral and environmental factors that contribute to its occurrence. ${ }^{1}$

Three distinct diagnostic criteria have been used, namely, the National Institutes of Health (NIH), the Rotterdam consensus, and the Androgen Excess and PCOS Society (AE-PCOS) criteria. The previous exclusion of pathologies presenting a similar clinical picture is important for all three diagnostic criteria. ${ }^{1}$

In addition to being an ovulatory disorder, PCOS can also be considered a metabolic disorder, since insulin resistance (IR) and consequent compensatory hyperinsulinemia, which are closely related to its pathogenicity and comorbidities, can be exacerbated by the coexistence of obesity, which affects $\sim 50 \%$ of PCOS women. ${ }^{2}$

However, IR is not part of the diagnostics criteria, partly and probably because of the absence of an accurate validated method for use in clinical practice, since the hyperinsulinemic-euglycemic clamp, the gold standard for diagnosing IR, is expensive and difficult to perform. ${ }^{3}$

It has been observed that, in addition to IR, PCOS patients are at a higher risk of developing glucose intolerance, Type 2
Diabetes Mellitus, dyslipidemia, and metabolic syndrome (MS), ${ }^{1,2}$ all of which are traditional risk factors for the development of cardiovascular diseases (CVDs).

Nevertheless, there remain uncertainties regarding the clinical outcomes and mortality due to CVD. ${ }^{4}$ Furthermore, the fact that these patients are predominantly young and often show normal lipid profile could be contributing to delays in their evaluation and in the adequate establishment of their clinical management. ${ }^{1,5}$

The purpose of this paper is to analyze the association between the indirect methods of evaluating IR and the blood pressure, anthropometric and biochemical parameters in a population of PCOS patients.

\section{Methods}

A cross-sectional study was performed at the Hospital Universitário de Brasília (HUB, in the Portuguese acronym) using information obtained from the records of patients diagnosed with PCOS from January 2011 to January 2013.

The population of the study included women 18 years of age or older with a PCOS diagnosis according to the Rotterdam criteria. ${ }^{5}$ Cases of thyroid dysfunction, hyperprolactinemia, congenital adrenal hyperplasia, Cushing syndrome, glucose intolerance, diabetes, ovarian or adrenal tumors, premature ovarian failure, patients who had used any hormonal or non- 
hormonal medication that could interfere with the results during the 6 months prior to the study, patients under 18 years of age, and records lacking any of the information required were excluded from the study.

In addition to demographic data, such as marital status, parity and age, the analysis included menstrual patterns, the existence of hyperandrogenism, acne, and acanthosis nigricans. Menstrual cycles were considered anovulatory when longer than 35 and shorter than 90 days, and amenorrheic in the absence of menstruation for at least 3 months, ${ }^{6}$ while hirsutism was defined as a Ferriman and Gallwey ${ }^{7}$ score of eight or more. Total blood testosterone was obtained using the chemiluminescence method, with values exceeding 80 $\mathrm{ng} / \mathrm{dL}$ considered altered.

The analysis of the anthropometric measurements included the body mass index (BMI) and the waist circumference (WC). The BMI was obtained using the Quetelet ${ }^{8}$ index, namely, the ratio of weight over height in square meters, and the results were subdivided into normal (18.5-24.9), overweight (25-29.9) and obese ( $\geq 30$ ). The WC was the smallest circumference between the last rib and the iliac crest, $^{8}$ with a cutting point at $88 \mathrm{~cm} .{ }^{9}$

Blood pressure (BP) and biochemical evaluation, through the analysis of the concentration of triglycerides, total cholesterol, high-density lipoprotein cholesterol (HDL-c), low density lipoprotein cholesterol (LDL-c), lipoproteins excluding HDL cholesterol (non-HDL-c), and fasting glucose were also evaluated. The parameters of normality, as well as the diagnostic criteria of MS were defined. ${ }^{9}$ In addition, the lipid accumulation product (LAP), ${ }^{10}$ which uses an anthropometric measurement (waist circumference) and a biochemical measurement (triglycerides), was also calculated and considered normal when lower than 34.5. ${ }^{11}$

Insulin Resistance was diagnosed using four indirect methods, namely, fasting blood insulin in excess of $12 \mu \mathrm{IU} /$ $\mathrm{mL},{ }^{12}$ the fasting blood glucose over fasting blood insulin ratio lower than $6.4,{ }^{12}$ homeostatic model assessment-insulin resistance(HOMA-IR), calculated using the Mathews formula, ${ }^{13}$ higher than $2.71,{ }^{14}$ and quantitative insulin sensitivity check index(QUICKI) lower than $0.333 .^{12}$

The Chi-square test $\left(\mathrm{X}^{2}\right)$ or the Fisher exact test (where recommended) were used to evaluate the association between the four indirect methods of evaluating IR and the blood pressure, anthropometric and biochemical parameters. Contingency tables were performed with IR diagnostic method and the BMI classified into groups (normal, overweight and obesity), and the test for equality of proportions was used to identify which groups were different from one another in terms of IR. The test of proportions was also used to evaluate the differences between the frequencies among the four IR diagnostic methods. The SAS 9.3 statistical software package (SAS Institute, Cary, NC, USA) was used and considered statistically significant when p 0.05 .

The study was approved by the Committee of Ethics in Research in Human Beings of the Faculdade de Ciências da Saúde da Universidade de Brasília (CAAE 14168613.3.0000.0030).

\section{Results}

After applying the inclusion and exclusion criteria, 83 PCOS patients were included in the study. Age varied from 18 to 42 years-old, $44.57 \%$ of patients being single and $51.8 \%$ nulliparous. In the clinical evaluation, $96.39 \%$ of the patients reported oligomenorrhea or amenorrhea, $73.49 \%$, hirsutism (Ferriman-Gallwey index), 48.19\%, acanthosis nigricans, $43.37 \%$, acne and one patient reported androgenic alopecia. Total testosterone exceeded $80 \mathrm{ng} / \mathrm{dL}$ in $18.29 \%$ of the patients, and $70 \mathrm{ng} / \mathrm{dL}$ in $50.60 \%$ of them. The clinical, anthropometric, blood pressure, and biochemical results are shown in - Table 1.

Insulin resistance was diagnosed in $66.27 \%$ of the cases using the QUICKI; in $60.24 \%$ by the fasting blood insulin; in $59.04 \%$ by the HOMA-IR; and in $51.81 \%$ by the fasting glucose/insulin $(\mathrm{G} / \mathrm{I})$ ratio. With regards to the frequency of IR, there was no significant difference among the methods analyzed according to the test of proportions ( $p=0.304)$. As shown in - Table 2, there was a statistically significant association between BMI and all the IR diagnostic methods, as well as between IR and WC. Regarding high blood pressure, no significant association was found for the $\mathrm{G} / \mathrm{I}$.

Obesity and overweight were diagnosed in $56.62 \%$ and $24.09 \%$ of the patients, respectively. Comparing the BMI groups two by two, the prevalence of IR was higher among

Table 1 Anthropometric, blood pressure and biochemical characteristics of the 83 patients with polycystic ovary syndrome

\begin{tabular}{|l|l|l|}
\hline Parameters & $\begin{array}{l}\text { Mean } \pm \text { Standard } \\
\text { Deviation }\end{array}$ & Reference \\
\hline Age (years) & $28.79 \pm 5.85$ & \\
\hline Weight $(\mathrm{Kg})$ & $76.43 \pm 13.91$ & \\
\hline Height $(\mathrm{cm})$ & $160.12 \pm 6.63$ & \\
\hline $\begin{array}{l}\text { Ferriman-Gallwey } \\
\text { score }\end{array}$ & $11.83 \pm 2.94$ & $<8$ \\
\hline Body mass index & $29.9 \pm 5.28$ & $18-25 \mathrm{~kg} / \mathrm{m}^{2}$ \\
\hline $\begin{array}{l}\text { Waist } \\
\text { circumference }\end{array}$ & $92.15 \pm 10.72$ & $<88 \mathrm{~cm}$ \\
\hline $\begin{array}{l}\text { Systolic blood } \\
\text { pressure }\end{array}$ & $123.15 \pm 18.38$ & $<130 \mathrm{~mm}$ \\
\hline $\begin{array}{l}\text { Diastolic blood } \\
\text { pressure }\end{array}$ & $79.13 \pm 11.00$ & $<85 \mathrm{~mm} \mathrm{Hg}$ \\
\hline Total cholesterol & $183.07 \pm 34.88$ & $\leq 200 \mathrm{mg} / \mathrm{dL}$ \\
\hline $\begin{array}{l}\text { High-density } \\
\text { lipoprotein }\end{array}$ & $49.47 \pm 12.91$ & $\geq 50 \mathrm{mg} / \mathrm{dL}$ \\
\hline $\begin{array}{l}\text { Low-density } \\
\text { lipoprotein }\end{array}$ & $117.16 \pm 32.74$ & $<100 \mathrm{mg} / \mathrm{dL}$ \\
\hline $\begin{array}{l}\text { Non-HDL } \\
\text { lipoproteins }\end{array}$ & $133.41 \pm 35.17$ & $<130 \mathrm{mg} / \mathrm{dL}$ \\
\hline Triglycerides & $110.6 \pm 59.09$ & $<150 \mathrm{mg} / \mathrm{dL}$ \\
\hline $\begin{array}{l}\text { Fasting blood } \\
\text { glucose }\end{array}$ & $87.74 \pm 6.52$ & $<100 \mathrm{mg} / \mathrm{dL}$ \\
\hline
\end{tabular}


Table 2 Association between insulin resistance and the anthropometric and blood pressure parameters in 83 patients with polycystic ovary syndrome

\begin{tabular}{|l|l|l|l|l|l|}
\hline Method & BMI & WC & SBP & DBP & AH \\
\hline Fasting insulinemia & $<0.0001^{*}$ & $<0.0001^{*}$ & $0.0019^{*}$ & $0.0099^{*}$ & $0.0118^{*}$ \\
\hline G/I & $0.0014^{*}$ & $<0.0001^{*}$ & 0.1225 & 0.2308 & 0.2866 \\
\hline HOMA-IR & $0.0002^{*}$ & $<0.0001^{*}$ & $0.0051^{*}$ & $0.0252^{*}$ & $0.0253^{*}$ \\
\hline QUICKI & $0.0001^{*}$ & $<0.0001^{*}$ & $0.0057^{*}$ & 0.0591 & $0.0348^{*}$ \\
\hline
\end{tabular}

Abbreviations: AH, arterial hypertension; BMI, body mass index; DBP, diastolic blood pressure; G/I, fasting blood glucose/fasting blood insulin ratio; HOMA-IR, homeostatic model assessment-insulin resistance; QUICKI, quantitative insulin sensitivity check index; SBP, systolic blood pressure; WC, waist circumference.

${ }^{*}$ Chi-square test. Significant association $(p<0.05)$.

(Full data are available in the supplemental file).

the obese patients regardless of the indirect method used, varying from $68.09-82.98 \%$ using the G/I and the QUICKI, respectively. In overweight women, IR varied from $50-55 \%$, while in normal BMI women, the highest IR value was $25 \%$, according to the QUICKI, and the lowest value was $18.75 \%$, as per the other three methods.

- Table 3 shows that the proportion of IR diagnoses was statistically higher in obese women when compared with the

Table 3 Test of proportions for the body mass index groups as related to the insulin resistance diagnostic methods

\begin{tabular}{|l|l|l|l|}
\hline Method & $\begin{array}{l}\text { Normal/ } \\
\text { Overweight }\end{array}$ & $\begin{array}{l}\text { Normal/ } \\
\text { Obesity }\end{array}$ & $\begin{array}{l}\text { Overweight/ } \\
\text { Obesity }\end{array}$ \\
\hline $\begin{array}{l}\text { Fasting } \\
\text { insulinemia }\end{array}$ & 0.1117 & $<0.0001^{*}$ & $0.0395^{*}$ \\
\hline G/I & 0.3119 & $0.0017^{*}$ & 0.0611 \\
\hline HOMA-IR & 0.1117 & $0.0001^{*}$ & 0.0629 \\
\hline QUICKI & 0.0779 & $<0.0001^{*}$ & 0.0881 \\
\hline
\end{tabular}

Abbreviations: G/I, fasting blood glucose/fasting blood insulin ratio; HOMA-IR, homeostatic model assessment- insulin resistance; QUICKI, quantitative insulin sensitivity check index.

(Full data are available in the supplemental file).

${ }^{*}$ Test of proportions; Significant difference between the proportions $(p<0.05)$. proportion of normal BMI patients in all methods of assessment. There was no difference in proportions of IR among normal weight and overweight women.

With regards to the biochemical parameters, the association between IR and the non-HDL-c level was statistically significant according to the QUICKI, while in the case of the triglycerides a statistical significance was found in the fasting blood insulin and the QUICKI ( - Table 4). - Table 4 also shows a statistically significant association among all the IR diagnostic methods and the LAP.

An analysis of the isolated parameters showed that $22.89 \%$ of the patients presented at least three diagnostic criteria for MS. And the $\mathrm{X}^{2}$ test showed a statistically significant association between those cases and all the IR diagnostic methods with $p=0.0005$ for fasting insulin, $p=0.0070$ for the $\mathrm{G} / \mathrm{I}$, $p=0.0021$ for the HOMA-IR, and $p=0.0004$ for the QUICKI.

\section{Discussion}

Polycystic ovary syndrome is one of the most common endocrine pathologies of women of bearing-age. Although its prevalence could be even higher when the Rotterdam diagnostic criteria ${ }^{5}$ are followed, a large percentage of the cases might not be diagnosed at the primary health service level. ${ }^{1,15}$ Also, these patients might not receive due attention from the metabolic and cardiovascular points of view,

Table 4 Association between insulin resistance diagnostic methods and the lipid accumulation product and biochemical variables in polycystic ovary syndrome patients

\begin{tabular}{|l|l|l|l|l|l|l|}
\hline Method & LAP & $\begin{array}{l}\text { Total Choles- } \\
\text { terol }\end{array}$ & HDL-c & LDL-c & Non-HDL-c & TG \\
\hline Fasting Insulinemia & $0.0001^{*}$ & 0.4863 & 0.1149 & 0.6782 & 0.0941 & $0.0099^{* \#}$ \\
\hline G/I & $0.0001^{*}$ & 0.1148 & 0.2689 & 0.6922 & 0.0816 & 0.1579 \# \\
\hline HOMA-IR & $0.0001^{*}$ & 0.4107 & 0.1786 & 0.5686 & 0.1448 & 0.0750 \# \\
\hline QUICKI & $0.0001^{*}$ & 0.2657 & 0.1623 & 0.9134 & $0.0190^{*}$ & $0.0252^{* \#}$ \\
\hline
\end{tabular}

Abbreviations: G/I, fasting blood glucose/fasting blood insulin ratio; HDL-c, high-density lipoprotein cholesterol; HOMA-IR, homeostatic model assessment-insulin resistance; LAP, lipid accumulation product; LDL-c, low-density lipoprotein cholesterol; Non- HDL-c, non-HDL cholesterol; QUICKI, quantitative insulin sensitivity check index; TG, triglycerides.

(Full data are available in the supplemental file).

${ }^{*}$ Chi-square test. Significant association $(p<0.05)$.

\#Fisher exact test. Significant association $(p<0.05)$. 
because their management tends to focus on their aesthetic and reproductive problems. ${ }^{1}$

Although its physiopathology is not quite understood, there is no doubt that IR plays an important role, since it leads to compensatory hyperinsulinemia with complex effects on the regulation of lipid metabolism, protein synthesis and modulation of androgen production, ${ }^{16}$ whose mechanism results from a defect in the insulin receptor characterized by increased serine phosphorylation. ${ }^{3}$

Nevertheless, the prevalence of IR has been an object of discussion. In our study, IR was found in $51.81-66.27 \%$ of the patients, depending on the diagnostic method employed, but it has been diagnosed in $50-80 \%$ of PCOS patients. ${ }^{1,12,16}$ Such great variability may result from the diagnostic criteria used in PCOS, different PCOS phenotypes, ethnic differences in insulin action, or even environmental factors such as diet, as well as the method used to identify IR. ${ }^{3}$

Because the complexity and cost of the hyperinsulinemiceuglycemic clamp for IR diagnosis make its use impractical for routine use in clinical practice, ${ }^{3}$ other measures have been employed, such as HOMA-IR, QUICKI and the G/I, 3,12 which appear effective in diagnosing IR. ${ }^{12}$ However, despite the statement that the HOMA-IR and QUICKI would be more sensitive in detecting IR, ${ }^{12}$ we have not observed a statistically significant difference among the four methods used in our study.

Insulin resistance may be found in PCOS patients with normal weight, but its frequency and magnitude increase in the presence of obesity. ${ }^{1,2,17}$ The average frequency of IR was $20.31 \%$ among normal weight patients, 50\% among overweight patients and $76.59 \%$ among obese patients in our study. We also observed a significantly higher proportion of IR among the obese patients when compared with normal weight patients. These findings are similar to those of ReyesMuñoz et al ${ }^{18}$ using HOMA. In addition, Moran et $\mathrm{al}^{17}$ observed a strong positive correlation between the magnitude of IR, measured using the G/I, and the women's BMI.

Obesity is an independent risk factor of developing $C D$ and it has been suggested that, independently from the BMI, PCOS women tend to accumulate fat in the visceral abdominal region, which confers them a metabolic risk. ${ }^{1}$

In our study, there was a statistically significant association between both anthropometric factors- BMI and WCand all the IR diagnostic methods. An extensive review published recently ${ }^{19}$ observed that the greatest health implications for PCOS patients are associated with excess weight and abdominal circumference, since visceral abdominal fat is associated with increasing IR. ${ }^{19}$

It has been observed that IR could promote $\mathrm{CD}$ directly and/or, indirectly, through changes in fibrinolysis, compromising lipolysis suppression and inducing arterial hypertension $(\mathrm{AH}){ }^{4}$

A Swedish study found that, even in the absence of a true hypertensive state, PCOS women had higher average blood pressure than the controls, even after adjusting for the BMI and body fat distribution ${ }^{20}$ and a Brazilian study observed the prevalence of $\mathrm{AH}$ two times higher in PCOS women than in non-PCOS women. ${ }^{21}$ In our study, we observed a statisti- cally significant association between $\mathrm{AH}$ and IR with three of the four diagnostic methods employed.

It has also been suggested that IR could contribute to the dyslipidemia frequently observed in PCOS patients through various mechanisms. While Slowińska-Srzednicka et $\mathrm{al}^{22}$ observed a positive correlation between total triglycerides and fasting insulin and a negative correlation between apolipoprotein A-I and fasting insulin in PCOS women, our study showed a significant association between the triglyceride levels and IR diagnosed using the QUICKI and the fasting blood insulin level. Furthermore, the frequent finding of high non-HDL-c in PCOS patients, seen in 53.01\% of the cases in our study, also reflects another cardiovascular risk factor in these women. ${ }^{19}$

Although dyslipidemia can occur independently of obesity, ${ }^{23} \mathrm{BMI}$ is believed to be the main determining factor for high triglyceride levels and reduced HDL levels, frequently found in PCOS. ${ }^{24}$

However, the LDL-c in PCOS seems less dependent on body weight and could be partially related to the hyperandrogenism frequently observed in these women. ${ }^{1,19}$ In our study, $73.49 \%$ of the patients showed hirsutism and in $18.29 \%$ of them total plasma testosterone exceeded $80 \mathrm{ng} / \mathrm{dL}$. Nevertheless, although the high LDL-c levels could be associated with hyperandrogenism, it is not clear whether there is a causal relation between them. ${ }^{1}$ Furthermore, the androgens could also contribute to IR by means of a direct effect on skeletal muscle and action on adipose tissue. ${ }^{3}$

It has also been reported that the menstrual pattern of these patients could contribute to the IR finding. Brower et $\mathrm{al}^{25}$ observed that, in PCOS women, when the menstrual cycle exceeded 35 days, HOMA-IR levels were higher than those of the controls or of PCOS women with regular cycles. In our study, $55.43 \%$ of the patients showed such menstrual cycle pattern and $40.96 \%$ were amenorrheic. Acanthosis nigricans, observed in $48.19 \%$ of the patients, cannot be forgotten, since a substantial percentage of PCOS patients suffer from this condition and its severity correlates with the degree of IR. ${ }^{26}$

Besides that, the metabolic abnormalities in PCOS patients can coincide with the diagnostic components of the MS, ${ }^{9}$ in which IR and compensatory hyperinsulinemia also play a crucial role in the physiopathology of the MS. ${ }^{27}$ Nevertheless, the prevalence of this syndrome can vary depending on the ethnicity, age, BMI, country, as well as the criteria used in defining both PCOS and the MS. ${ }^{28}$ Despite having excluded the analysis the patients' charts with fasting glucose higher than $100 \mathrm{mg} / \mathrm{dL}, 22.89 \%$ of the patients in our study had at least three parameters altered the normalcy standards, which would comply with the MS diagnostic criteria, ${ }^{9}$ reinforcing the higher cardiovascular risk in PCOS women.

In addition, we observed a statistically significant association between all the indirect methods of diagnosing IR and the presence of at least three diagnostic parameters for MS. The most prevalent association involved high WC (68.67\%) and low HDL (50\%). These findings are similar to those of Madani et $\mathrm{al}^{28}$ who also observed a higher prevalence of 
those two criteria, although decreased HDL was the most frequently observed alteration in their study.

The LAP index, combining the WC measurement and the triglyceride levels, was initially tested in 2005. The results suggested that it could become a predictor of $C D$ incidence. ${ }^{10}$

The LAP has been shown to be more accurate than HOMAIR in the diagnosis of IR. ${ }^{29}$ While Macut et al $^{30}$ observed an association between HOMA-IR and LAP, we observed a statistically significant association between LAP and all the methods of diagnosing IR. So that LAP could be an indicator of IR and other possible comorbidities related to this metabolic disorder, including CD in PCOS patients, in agreement with the previously observed findings. ${ }^{11}$ Nascimento et $\mathrm{al}^{31}$ corroborated this statement in a study of PCOS patients in which the researchers found an association between LAP and various cardiovascular risk parameters.

Some limitations in our study should be mentioned, particularly concerning the diagnosis of PCOS and MS. In regard to MS, we used internationally accepted criteria, ${ }^{9}$ and although we did not use the five classic measures for MS diagnosis, since fasting blood glucose level was excluded from the statistical analysis, we did use the other four to demonstrate the important metabolic disorders occurring in these patients and the significant association with IR.

Although the new PCOS guidelines suggest modifications in one of the diagnostic criteria by increasing the number of follicles to 25 because of new technologies for ultrasonography examination, the ovary size was not influenced by this innovation and $10 \mathrm{~cm}^{3}$ is still the cut-off point between a normal and an increased ovary. ${ }^{32}$ Thus, we based our diagnoses on the size of the ovary alone, rather than in the number of follicles. In addition, the guidelines of the Endocrine Society issued in 2013 suggested the use of the Rotterdam criteria for the diagnosis of PCOS. ${ }^{33}$

The gold standard in the diagnosis of IR is the hyperinsulinemic-euglycemic clamp. Nevertheless, this method is too expensive and elaborate for use in clinical practice. The diagnosis was established using four indirect methods, and it has been shown the mathematical methods, such as HOMAIR and QUICKI, have a good correlation with the clamp. ${ }^{12,34}$ Furthermore, they are sensitive enough to detect IR in PCOS. ${ }^{12}$ In addition, no statistical differences were found among the four methods, which could facilitate the initial identification of the patients suffering from IR at the primary health care level. Thus, more complex calculations would be avoided, and the patients referred to other specific clinical evaluations much sooner.

It is also important to mention that this study evaluated an institutional rather than a population-based sample, so the real prevalence of IR and cardiovascular risk factors in PCOS women could not be determined. Also, even though we have observed various associations between IR and these factors, like others in the literature, ${ }^{11,18,28,30}$ the crosssectional design cannot infer causal relationships between IR, obesity, dyslipidemia and PCOS.

Another limitation, albeit unrelated to the study per se, results from the possible repercussions of the findings. The average age of the patients was 28.79 years, similarly to that of other studies in the literature. ${ }^{15,28,30,31}$ It could be assumed, therefore, that the existence of high metabolic risk in the young PCOS patients could predispose them to $C D$ as they grow older. ${ }^{19}$

However, the actual incidence of $\mathrm{CD}$ and mortality is still under dispute. While a 21-year follow-up study of a cohort of Swedish PCOS patients did not find increased myocardial infarct, stroke or mortality, despite the higher prevalence of $\mathrm{AH}$ and dyslipidemia in these women, ${ }^{35}$ a prospective Iranian study with a 12-year follow-up of PCOS patients and controls did not find any significant difference in the cardiac-metabolic risk factors between the two groups. ${ }^{4}$ Besides that, it was also found that the difference in insulin levels and IR, initially higher in the PCOS group, diminished along time. ${ }^{4}$ Nevertheless, a recent meta-analysis observed a significant association between PCOS and coronary heart disease, although no association was found between PCOS and myocardial infarction. ${ }^{36}$

It is possible that the heterogeneous nature of the PCOS, the lack of knowledge about its physiopathology and the existence of exogenous factors and other confounding elements, such as obesity, make it difficult to evaluate with any degree of precision the extension of the long-term complications of the syndrome. ${ }^{19}$ In addition, changes in metabolic regulation and ovarian function could also modify the expression of the disease and act over its morbidity. ${ }^{19}$

Nevertheless, despite the controversies about the future of these patients, we cannot ignore the findings of our study: a series of independent and associated factors of cardiovascular risk, such as the existence of IR and its significant association with WC, BMI, LAP, as well as dyslipidemia and $\mathrm{AH}$ in a high proportion of patients.

Early detection of those metabolic and cardiovascular risk factors by the primary health care services through the use of simple measures, such as the anthropometric evaluation of the patients and LAP, would lead to appropriate counseling regarding the patients' lifestyle or to the prescription of medications that could improve their quality of life and reduce the risk of PCOS' long term complications, which increase considerably the costs of the health care provided.

\section{Conclusion}

Insulin resistance was found in $51.81-66.2 \%$ of the patients, with no significant difference between the four methods analyzed. The proportion of IR diagnoses was statistically higher in obese women than in women with normal BMI. A statistically significant association was observed between IR and WC, BMI, LAP, as well as dyslipidemia and AH in a high proportion of patients.

\section{Contributors}

Wanderley M. S., Pereira L. C. R., Santos C. B., Cunha V. S. and Neves M. V. J. contributed with project and interpretation of data, writing of the article, critical review of the intellectual content and final approval of the version to be published. 
Conflicts of Interest

The authors have no conflict of interest to disclaim.

\section{References}

1 Baldani DP, Skrgatic L, Ougouag R. Polycystic ovary syndrome: important underrecognised cardiometabolic risk factor in reproductive-age women. Int J Endocrinol 2015;2015:786362

2 Laganà AS, Rossetti $\mathrm{P}$, Buscema $\mathrm{M}$, et al. Metabolism and ovarian function in PCOS women: a therapeutic approach with inositols. Int J Endocrinol 2016;2016:6306410

3 Diamanti-Kandarakis E, Dunaif $A$. Insulin resistance and the polycystic ovary syndrome revisited: an update on mechanisms and implications. Endocr Rev 2012;33(06):981-1030. Doi: 10.1210/er.2011-1034

4 Ramezani Tehrani F, Montazeri SA, Hosseinpanah F, et al. Trend of cardio-metabolic risk factors in polycystic ovary syndrome: a population-based prospective cohort study. PLoS One 2015;10 (09):e0137609. Doi: 10.1371/journal.pone.0137609

5 Rotterdam ESHRE/ASRM-Sponsored PCOS consensus workshop group. Revised 2003 consensus on diagnostic criteria and longterm health risks related to polycystic ovary syndrome (PCOS). Hum Reprod 2004;19(01):41-47. Doi: 10.1093/humrep/deh098

6 De Leo V, Musacchio MC, Cappelli V, Massaro MG, Morgante G, Petraglia F. Genetic, hormonal and metabolic aspects of PCOS: an update. Reprod Biol Endocrinol 2016;14(01):38. Doi: 10.1186/ s12958-016-0173-x

7 Ferriman D, Gallwey JD. Clinical assessment of body hair growth in women. J Clin Endocrinol Metab 1961;21:1440-1447. Doi: 10.1210/jcem-21-11-1440

8 World Health Organization. Obesity: Preventing and Managing the Global Epidemic: Report of a WHO Consultation. Geneva: WHO; 1997

9 National Cholesterol Education Program (NCEP) Expert Panel on Detection, Evaluation, and Treatment of High Blood Cholesterol in Adults (Adult Treatment Panel III). Third Report of the National Cholesterol Education Program (NCEP) Expert Panel on Detection, Evaluation, and Treatment of High Blood Cholesterol in Adults (Adult Treatment Panel III) final report. Circulation 2002;106(25): 3143-3421

10 Kahn HS. The "lipid accumulation product" performs better than the body mass index for recognizing cardiovascular risk: a population-based comparison. BMC Cardiovasc Disord 2005;5:26. Doi: 10.1186/1471-2261-5-26

11 Wiltgen D, Benedetto IG, Mastella LS, Spritzer PM. Lipid accumulation product index: a reliable marker of cardiovascular risk in polycystic ovary syndrome. Hum Reprod 2009;24(07):1726-1731. Doi: 10.1093/humrep/dep072

12 Carmina E, Lobo RA. Use of fasting blood to assess the prevalence of insulin resistance in women with polycystic ovary syndrome. Fertil Steril 2004;82(03):661-665. Doi: 10.1016/j.fertnstert.2004.01.041

13 Matthews DR, Hosker JP, Rudenski AS, Naylor BA, Treacher DF, Turner RC. Homeostasis model assessment: insulin resistance and beta-cell function from fasting plasma glucose and insulin concentrations in man. Diabetologia 1985;28(07):412-419. Doi: 10.1007/BF00280883

14 Geloneze B, Repetto EM, Geloneze SR, Tambascia MA, Ermetice MN. The threshold value for insulin resistance (HOMA-IR) in an admixtured population IR in the Brazilian Metabolic Syndrome Study. Diabetes Res Clin Pract 2006;72(02):219-220. Doi: 10.1016/j.diabres.2005.10.017

15 Ding T, Baio G, Hardiman PJ, Petersen I, Sammon C. Diagnosis and management of polycystic ovary syndrome in the UK (20042014): a retrospective cohort study. BMJ Open 2016;6(07): e012461. Doi: 10.1136/bmjopen-2016-012461

16 Teede H, Deeks A, Moran L. Polycystic ovary syndrome: a complex condition with psychological, reproductive and metabolic manifestations that impacts on health across the lifespan. BMC Med 2010;8:41. Doi: 10.1186/1741-7015-8-41
17 Moran C, Arriaga M, Rodriguez G, Moran S. Obesity differentially affects phenotypes of polycystic ovary syndrome. Int J Endocrinol 2012;2012:317241

18 Reyes-Muñoz E, Ortega-González C, Martínez-Cruz N, et al. Association of obesity and overweight with the prevalence of insulin resistance, pre-diabetes and clinical-biochemical characteristics among infertile Mexican women with polycystic ovary syndrome: a cross-sectional study. BMJ Open 2016;6(07):e012107. Doi: 10.1136/bmjopen-2016-012107

19 Palomba S, Santagni S, Falbo A, La Sala GB. Complications and challenges associated with polycystic ovary syndrome: current perspectives. Int $\mathrm{J}$ Womens Health 2015;7:745-763. Doi: 10.2147/IJWH.S70314

20 Holte J, Gennarelli G, Berne C, Bergh T, Lithell H. Elevated ambulatory day-time blood pressure in women with polycystic ovary syndrome: a sign of a pre-hypertensive state? Hum Reprod 1996;11(01):23-28. Doi: 10.1093/oxfordjournals.humrep. a019028

21 Martins WdeP, Soares GM, Vieira CS, dos Reis RM, de Sá MF, Ferriani RA. [Cardiovascular risk markers in polycystic ovary syndrome in women with and without insulin resistance]. Rev Bras Ginecol Obstet 2009;31(03):111-116. Doi: 10.1590/S010072032009000300002

22 Slowińska-Srzednicka J, Zgliczyński S, Wierzbicki M, et al. The role of hyperinsulinemia in the development of lipid disturbances in nonobese and obese women with the polycystic ovary syndrome. J Endocrinol Invest 1991;14(07):569-575

23 Wild RA, Rizzo M, Clifton S, Carmina E. Lipid levels in polycystic ovary syndrome: systematic review and meta-analysis. Fertil Steril 2011;95(03):1073-9.e1, 11

24 Bass KM, Newschaffer CJ, Klag MJ, Bush TL. Plasma lipoprotein levels as predictors of cardiovascular death in women. Arch Intern Med 1993;153(19):2209-2216. Doi: 10.1001/ archinte.1993.00410190045006

25 Brower M, Brennan K, Pall M, Azziz R. The severity of menstrual dysfunction as a predictor of insulin resistance in PCOS. J Clin Endocrinol Metab 2013;98(12):E1967-E1971. Doi: 10.1210/ jc.2013-2815

26 Dunaif A, Green G, Phelps RG, Lebwohl M, Futterweit W, Lewy L. Acanthosis Nigricans, insulin action, and hyperandrogenism: clinical, histological, and biochemical findings. J Clin Endocrinol Metab 1991;73(03):590-595

27 Zahiri Z, Sharami SH, Milani F, et al. Metabolic syndrome in patients with polycystic ovary syndrome in Iran. Int J Fertil Steril 2016;9(04):490-496. Doi: 10.22074/ijfs.2015.4607

28 Madani T, Hosseini R, Ramezanali F, et al. Metabolic syndrome in infertile women with polycystic ovarian syndrome. Arch Endocrinol Metab 2016;60(03):199-204. Doi: 10.1590/23593997000000135

29 Malavazos AE, Cereda E, Ermetici F, et al. The "lipid accumulation product" is associated with 2-hour postload glucose outcomes in overweight/obese subjects with nondiabetic fasting glucose. Int J Endocrinol 2015;2015:836941

30 Macut D, Božić Antić I, Bjekić-Macut J, et al. Lipid accumulation product is associated with metabolic syndrome in women with polycystic ovary syndrome. Hormones (Athens) 2016;15(01): 35-44. Doi: 10.14310/horm.2002.1592

31 Nascimento JX, Chein MB, de Sousa RM, Ferreira AdosS, Navarro PA, Brito LM. Importance of lipid accumulation product index as a marker of CVD risk in PCOS women. Lipids Health Dis 2015;14:62. Doi: 10.1186/s12944-015-0061-y

32 Dewailly D, Lujan ME, Carmina E, et al. Definition and significance of polycystic ovarian morphology: a task force report from the Androgen Excess and Polycystic Ovary Syndrome Society. Hum Reprod Update 2014;20(03):334-352. Doi: 10.1093/humupd/ dmt061

33 Legro RS, Arslanian SA, Ehrmann DA, et al; Endocrine Society. Diagnosis and treatment of polycystic ovary syndrome: an 
Endocrine Society clinical practice guideline. J Clin Endocrinol Metab 2013;98(12):4565-4592. Doi: 10.1210/jc.2013-2350

34 Otten J, Ahrén B, Olsson T. Surrogate measures of insulin sensitivity vs the hyperinsulinaemic-euglycaemic clamp: a meta-analysis. Diabetologia 2014;57(09):1781-1788

35 Schmidt J, Landin-Wilhelmsen K, Brännström M, Dahlgren E. Cardiovascular disease and risk factors in PCOS women of post- menopausal age: a 21-year controlled follow-up study. J Clin Endocrinol Metab 2011;96(12):3794-3803. Doi: 10.1210/ jc.2011-1677

36 Zhao L, Zhu Z, Lou $\mathrm{H}$, et al. Polycystic ovary syndrome (PCOS) and the risk of coronary heart disease (CHD): a metaanalysis. Oncotarget 2016;7(23):33715-33721. Doi: 10.18632/ oncotarget.9553 